and inconsistencies which Dr Lantos probes are not unique to American medicine and, with the increasing move to globalism, they have relevance and resonance for others. Indeed, the past ten years in the United Kingdom have seen a re-organisation of the National Health Service (NHS) on purchaser/provider lines, establishment of evidence-based medicine and clinical guidelines, and the beginnings of managed care. We too have been preoccupied with the political, sociological and economic factors that $\mathrm{Dr}$ Lantos categorises, with the human genome project, the advances of technology and bioethics, and we have witnessed the decline of the generalist be $\mathrm{s} /$ he surgeon, physician or paediatrician.

Each chapter uses a broadly similar format to deal with specific issues which face doctors but seen through a paediatrician's eyes. As such, some of the particular problems-for example those related to paternalism encompassed in the chapters on Truth, story, fiction and lies and On mistakes and truth telling-are perhaps of less interest to an adult specialist. As Dr Lantos remarks: "As with most modern bioethical paradigms all bets are off when it comes to paediatrics". $\mathrm{He}$ argues that there is a dichotomy between legal obligations which are largely owed to the parents and moral obligations which are largely but not entirely owed to the child. It is this intriguing distinction which will interest paediatricians because it recurs throughout the book. There are accounts of fractionation of total care once provided by doctors, of shifts in management structure, of medical practice which is increasingly dehumanised and increasing economically and legally orientated. He describes the "hollowing out" of doctors and the alienation which may accompany the practice of high technology medicine and ponders whether this need always be the price that we pay for progress.

Anecdotes and case histories are used to provide the power to move and to lead us to question what we do in relation to our own practice. The description of an unsuccessful attempt to resuscitate a close relative, for example, both illustrates notions of utility and helps to affirm and value the life of someone who is dying. The case of a child with campomelic dwarfism helps focus our views on futility and what may be in a child's best interests - and who decides what those best interests are. It is interesting to speculate what would happen to this particular child in the UK if a court were to apply the UK standards of best interests; this would be especially relevant given the recent publication of a Framework of Practice for Withdrawing or Withholding Life Sustaining Treatment by the Royal College of Paediatrics and Child Health. Indeed the whole issue of best interests raises important questions as to whether best interests standards can ever be applied from a child's perspective or be separate from our own and society's views on the future of children. I would have liked more analysis in this particular chapter.

Naturally, Lantos is concerned with how future doctors should be educated and those who contemplate studying medicine or are studying it could do a lot worse than read this book. One chapter is largely devoted to one of Lantos's mentors who ironically died of liver failure in the largest liver transplant unit in the world. Many doctors will have known and appreciated such teachers as Ken Schuit, but how often is their workload and contribution valued? In a passage which echoes some of the sentiments expressed by Earl Spencer at The Princess of Wales's funeral, Lantos wonders whether morality is something that we can't define and which we can only recognise when it is gone. Lantos finally examines the inexorable march of medicinal progress and the inconsistencies, incompatibilities and ambivalence which surround it. $\mathrm{He}$ questions whether, for example, randomised controlled trials can produce answers to all the questions we wish to ask. He discusses whether medicine is a moral enterprise with its own values or a technical exercise which is morally neutral and argues that our response will condition the kind of doctors which we want. In a significant passage he regards "the doctor who must gain informed consent according to a legally defined protocol in order to provide treatment that the patient's insurance company [substitute provider] has approved because it is the most cost effective and who then provides the treatment according to a practice guideline based on valid outcome studies is a very different creature from any doctor who has ever practised before". Indeed he is, if he practises without the art and humanity of the physician and without taking into account the intricacies of the doctor-patient relationship.

The last clinical example, that of a teenager with sickle cell disease whom

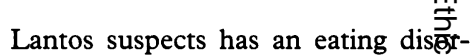
der, is perhaps the most telling in the

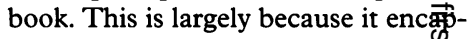
sulates the frustration of a doctor who, though a good doctor by most staredards, cannot relieve the pain he sees behind a patient's eyes.

There are a few caveats. Those who wish formulaic answers in this book will not find them; this is a book to provide questions, to give us pause क्षr thought, rather than to provide sothtions. It is written from an Amerigen perspective and a glossary of some- of the terms might be helpful. It wo be difficult to judge (as a paediakioician) what impact this book wouीd make on non-paediatricians or nQ⿹clinicians and indeed it is not clear for whom this book is intended. However, all those who care about the direction in which medicine is going and all those who believe that there is art well as science in medicine shoüd read it. Those who neither believe care should also read this book to open their eyes as to what many doctors and patients feel.

VICTOR LARCH

Queen Elizabeth Hospital, Hackney R $\overline{\bar{a}}$, London E2 क्षे

\section{Living With One's Past. Personal Fates and Moral Pain}

Norman S Care, Lapham, Marylarud, Rowman and Littlefield, 1996, xiii $\stackrel{\overbrace{}}{9}$ 203 pages, $\$ 22.95$ (pb), $\$ 57.50$ (h⿱⺈⿵⺆⿻二丨冂口).

This book is undoubtedly erudite. only is there a breadth of philosophteal learning, but, amongst others, Camưंs, Tolstoy and William James are giwn an airing, and some perceptive comments on Arthur Miller's play Deat $\$ f$ a Salesman are woven into the text. So I enjoyed reading it and found plenty that was stimulating. But I was creft with a question about its ove coherence as a book.

Chapter one establishes that "the human condition is such that man us are or will be condemned by Фur pasts to be without peace of miffd" (page 24). The force of the auth@r's immediate question to himself, $\underbrace{\text { s }}$ so what?", is not tempered by his admission that "living with one's past problem without a solution" (p⿳亠丷厂犬ge 24). Somewhat later he states people are, in part, their histories, which may contain genetic and 
environmental factors of which we are ignorant, "or, in my own case, about which I deceive myself or suffer misunderstanding" (page 92). Given this fact (of "differential constitutional luck"), is there a "normative message" about how one should think, live and act (page 92)? It is suggested that working this out is one of the main tasks of the book. And the answer is largely that we "could be easier on the people around us", whilst at the same time recognizing that constitutional luck does not make us "helpless, unthreatening, or eager to change" (page 93). Professor Care is not unaware of the real world, but I wonder if the whole thrust of his message boils down simply to the biblical injunction to "judge not"? This includes, for Care, not judging oneself (too harshly anyway). My concern is that, whilst it is well demonstrated that we are flawed, our need to make judgments - sometimes of a highly critical kind - is not given enough weight. Moreover, if the philosophical issues surrounding the necessity for judgments of value are stirred up, they are not settled in these pages.

The middle three chapters (if I can paraphrase) argue respectively: that when we judge others we do so from within our value systems, which involves imposing our own value judgments; that we are not (as is commonly supposed) wholly rational and "in-control" agents, but are subject to constitutional luck; and, that when it comes to justice, we should be treated as individuals with differences. This is all fine and dandy, but it struck me (as a psychiatrist) that I should still recommend compulsory detention of the next person I assess in the police cells who is expressing violent intentions on the basis of psychotic symptoms. This sort of reality is hardly addressed in the book.

Instead, after numerous intimations, we are treated in the final chapter to a panegyric on the Twelve Steps of Alcoholics Anonymous (AA). Through AA's "many practices, steps, patient people, weird and funny stories, and endless bad coffee" people are enabled to live with their pasts and "achieve a sort of inner calm" (page 153). Well, but it doesn't work for everyone (which Care knows), and what about a close confiding relationship, Zen Buddhism, or Confession in the Roman Catholic Church, with more or less bad coffee? Why is AA here? And what is the book really about? AA?
This is perhaps too harsh, because the book is well written and interesting. Themes which engaged me included much of the discussion of alcoholism and the attitude we should take towards it and other psychiatric disorders. Nevertheless, some of this amounted to tilting at windmills (who would "demand" that someone with mere shyness should be treated (page 86)?). Of central importance, I thought, was much of the analysis of what it is to be a person and the normativity involved in our use of the concept. The conception we have of the person underlies all sorts of other attitudes (to death, for example). "Person-to-person fairness" and the need for "positive other-regarding attitudes of tolerance and generosity" (page 101) are clearly laudable and would not go amiss in medical practice.

I (sadly) cannot recommend the book as an important work in medical ethics. Those with an interest in the concept of the person and issues surrounding psychology and mental health might wish to dip into it. Advocates of AA will enjoy chapter five; philosophers might prefer the middle chapters.

JULIAN C HUGHES

Department of Old Age Psychiatry, Fair Mile Hospital, Cholsey, Oxfordshire

\section{Caring: Nurses, Women and Ethics}

\section{Helga Kuhse, Oxford, Blackwell, 1997, 296 pages, US\$21.95 (pb).}

Writing from her feminist perspective, the author offers timely and provocative insights regarding issues of concern to nurses, physicians and society more generally. The author's arguments are well crafted, and the text is eminently readable. At the same time, there are numerous points on which further comment would be desirable; four such points can be addressed briefly here.

1 Kuhse writes that there appear to be no good reasons justifying a role for nurses as subservient to doctors or medicine; "subservient" is here understood as "inferior" with reference to moral authority. Its use is grounded in a cursory sketch of nursing history and review of several metaphors ("woman $=$ wife/mother $/$ helpmate to man = nurse = helpmate to doctor"; "nurse = dutiful soldier $=$ unthinking machine"). In this context, Kuhse argues strongly against continuance of any subservient nursing posture (particularly as defended by Newton, 1981), noting first that this will cause more harm than benefit to patients, even as it could contribute to the demoralization of nurses. Further, a distinction must be made between the physician's medical and ethical authority. While the nurse might be bound, prima facie, to accept a medical judgment, that response provides insufficient reason to accept the physician's judgment qua ethical as superior to the judgment of the nurse qua ethical.

Missing here is exploration of an alternate contemporary concept, that of the health care team, particularly as concerns collective moral decisionmaking and/or moral consensus building. Can team advocacy, even granting its difficulty of implementation, not serve the patient's and the nurse's interests more successfully than nurse-doctor competition concerning moral authority? Missing here as well is reference to the limit, if any, regarding the moral authority of the patients; will it ever be subservient to the moral authority of the doctor, or the nurse, for that matter?

2 Kuhse argues that nursing ethics should be grounded in caring and impartiality "in the context of a universally accessible moral language of principles, rights or rules and, at times, legislation".

Basic here is the author's concept of a "minimum conception of ethics" and her understanding of the development of feminism (commencing with Gilligan à la "caring"). Confident in her view that "any association between gender and the moral approach [is more likely to be based] in historical and cultural conditions", the author provides critiques of several moral approaches: traditional ethics, "principles and rules", and "partialism" as replacing "impartialism". The discussion concludes with the view that women should accept a morality which embraces the concepts expressed above.

Of particular value in the nursing ethics portion of the text which follows is Kuhse's detailed criticism of Noddings's work (Caring: $A$ Feminine Approach to Ethics and Moral Education, 1984). Kuhse shares Noddings's view that "caring" is essential in grounding nursing ethics. Contrary to Noddings, however, Kuhse argues for "dispositional caring": a "willingness and openness to apprehend the 